\title{
Therapeutic effect of Sinapic acid in aluminium chloride induced dementia of Alzheimer's type in rats
}

\author{
Souravh Bais $^{1 \bowtie}$, Renu Kumari ${ }^{1}$, Yash Prashar ${ }^{1}$ \\ Department of Pharmacology, Rayat Institute of Pharmacy, Railmajra, SBS Nagar District, Punjab 144533, India
}

\begin{tabular}{|c|c|}
\hline ARTICLE INFO & ABSTRACT \\
\hline $\begin{array}{l}\text { Article history: } \\
\text { Received } 10 \text { May } 2017 \\
\text { Received in revised form } 18 \text { May } 2017 \\
\text { Accepted } 27 \text { May } 2017 \\
\text { Available online } 1 \text { July } 2017\end{array}$ & $\begin{array}{l}\text { Objective: To evaluate the effect of sinapic acid against Aluminium chloride-induced dementia } \\
\text { of Alzheimer's disease (AD) type in rat. Methods: The study was designed to induce dementia } \\
\text { by chronic exposure of aluminium chloride at a dose of } 175 \mathrm{mg} / \mathrm{kg} \text {, p.o. for a period of } 25 \text { days } \\
\text { in rats and then divided into different groups, i.e. Treatment group, negative control and two }\end{array}$ \\
\hline $\begin{array}{l}\text { Keywords: } \\
\text { Dementia } \\
\text { Alzheimer's disease } \\
\text { Aluminium chloride } \\
\text { Sinapic acid } \\
\text { Pharmacological } \\
\text { Biochemical } \\
\text { Histopathology }\end{array}$ & $\begin{array}{l}\text { groups of sinapic acid, (at a dose of } 20 \text { and } 40 \mathrm{mg} / \mathrm{kg} \text {, p.o.), where these groups treated and } \\
\text { observed till the } 35 \text { th day of experimental trial. The behavioural, neuronal and biochemical } \\
\text { parameters were determined during or end of experiment. Histological changes in the brain } \\
\text { were also observed. Results: Aluminium chloride at a dose of } 175 \mathrm{mg} / \mathrm{kg} \text {, o.p. had significantly } \\
\text { induced the dementia and sinapic acid, at a dose of } 40 \mathrm{mg} / \mathrm{kg} \text {, p.o., possessed therapeutic } \\
\text { effect against Aluminium chloride induced-dementia of AD type in rats. Conclusions: Sinapic } \\
\text { acid is a class of compound wide spread in plant kingdom and could be a better source of } \\
\text { neutraceuticals in brain disorders. The compound showed an in vivo MAO-A and MAO-B } \\
\text { inhibiting activity and their role in Alzheimer's disease type of dementia was unexplored. The } \\
\text { article also provides information on acute toxicity of sinapic acid with no toxicological sign on } \\
\text { brain with chronic dose of } \mathrm{AlCl}_{3} \text {. }\end{array}$ \\
\hline
\end{tabular}

\section{Introduction}

Dementia is a chronic or progressive disease affecting 24.3 million people worldwide in nature. There are disturbances and often gradual decrease in multiple higher cortical functions, including memory, thinking, remembering, orientation, comprehension, calculation, learning capacity, language, judgement, mood, confusion, and change in personality and other behavioral changes[1,2]. It is more common in people over 65 of age. Therefore, the main risk factor for dementia is age[3]. The terms senile and pre-senile dementia had been used to differentiate between patients under or over 65 years, but these are no longer in common use because the two types share some etiological features[4].

There is no cure for dementia. Cholinesterase inhibitors such as

Corresponding author: Souravh Bais, Department of Pharmacology, Rayat Institute of Pharmacy, Railmajra, SBS Nagar District, Punjab 144506, India.

E-mai: souravh2008.123@rediffmail.com donepezil are often used and may be beneficial in mild to moderate disease[5]. The sinapic acid is already reported as cholinesterase inhibitors (in vitro)[24] and the present study were aimed to evaluate the therapeutic potential of sinapic acid in $\mathrm{AlCl}_{3}$ induced dementia with special reference to its anticholine esterase inhibition activity (in vivo) and modulation of monoamine oxidase (MAO) in dementia.

Alzheimer's disease (AD) is a progressive and irreversible neurodegenerative disease, which damages and kills brain cells, manifested by deterioration in memory and cognition, impairment in performing activities of daily living, and many behavioral neuropsychiatric illnesses[6].

The pathological indications of $\mathrm{AD}$ are senile plaques, which are spherical accumulations of the protein -amyloid accompanied by degenerating neuronal processes, and neurofibrillary tangles, composed of paired helical filaments and other proteins. This corresponds to the clinical features of marked impairment of memory and abstract reasoning, with preservation of vision and movement[7].

The selective deficiency of acetylcholine in $\mathrm{AD}$, has given rise 
to the "cholinergic hypothesis," which proposes that a deficiency of acetylcholine is critical in the genesis of symptoms of $\mathrm{AD}[8]$ Therefore, a major approach for the treatment of $\mathrm{AD}$ has involved attempts to augment the cholinergic function within the brain. This involves the use of acetyl cholinesterase inhibitors such as rivastigmine, donepezil, tacrine and galantamine[9]. The more reactive oxygen species (ROS) will lead to imbalance between the formation of cellular oxidants and the anti-oxidative processes Oxidative metabolism of acetylcholine plays an important role in AD pathogenesis[10,11]. Sinapic acid is also possessed a significant antioxidant and anti inflammatory property, so the aim of present study is focused on modulation of various neurochemicals by sinapic acid in brain tissues.

Sinapic acid is a small naturally-occurring hydroxycinnamic acid and a member of the phenylpropanoid family. It has been proposed as a potent antioxidant by many researchers[12,13]. Sinapic acid is widespread in the plant kingdom (fruits, vegetables, cereal grains, oilseed crops, and some spices and medicinal plants) and as such is common in the human diet.

The previous reported pharmacological activities of sinapic acid are antioxidant and free-radical scavenging property, Antioxidant and cardioprotective, Antihypertensive and cardiovascular remodeling[14], Antihyperglycemic action[15], Anti-anxiety activity[16], Anticancer activity[17], Neuroprotective activity[18], Anti-inflammatory activity[19], Hepatoprotective and Anti fibrotic effects[20], Antimicrobial activity[21] and Hypolipidemic activity[22,23].

Sinapic acid is 3,5-dimethoxy-4-hydroxycinnamic acid. It may be found in the free form, but like other hydroxycinnamic acids, it is also found in the form of esters (Figure 1).

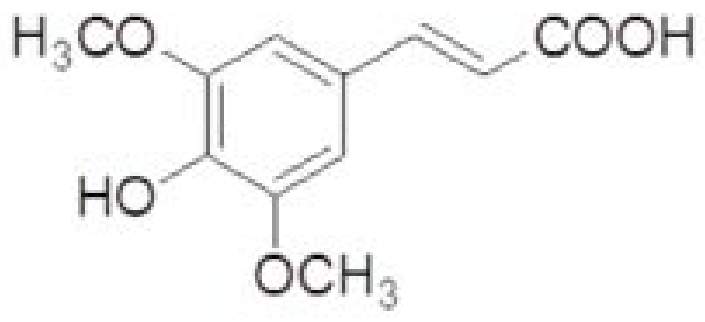

Figure 1. Structure of sinapic acid.

\section{Materials and methods}

\subsection{Drugs and chemicals}

Sinapic acid[SLBK4211V] (Pubchem CID 637775) was purchased from Sigma Aldrich (S \& G Lab Supplies). Rivastigmine tartrate was procured as a gift sample from Sun pharmaceutical Pvt. Ltd. Baddi (H.P.) India. Chemicals like aluminium chloride, DTNB, acetylthiocholine iodide, trichloroacetic acid, thiobarbituric acid, sodium carboxy methyl cellulose was procured from Himedia Pvt. Ltd. (Mumbai) S.D. Fine Chemicals Ltd. (Mumbai). Solvents like methanol, chloroform, dichloromethane, tween 80, n-butanol and ethyl acetate were of analytical grade (AR).

\subsection{Animals}

Age matched young wistar albino rats of either sex, weighing 120-150 g were selected for the study. The animals were kept in the paddy husk as bedding material. Husk changed every day. The animals were housed in a group of 6 ( 2 male, 4 Female) per polypropylene cages kept under controlled room temperature $(25 \pm 1$ $\left.{ }^{\circ} \mathrm{C}\right)$ in 12 hours light - dark cycle. The rats were allowed free access to food (Standard pallet) and water. The experiment was conducted in a noise-free environment between 9:00 AM to 2:00 PM. All procedures were approved and carried out as per the guidelines of Committee for purpose Control and Supervision of Experiments on Animals (CPCSEA) [CPCSEA Reg. No. 874/PO/Re/S/2005/ CPCSEA].

\subsection{Acute toxicity study}

$\mathrm{LD}_{50}$ was determined according to the guidelines of organization for economic cooperation \& development (OECD) following the up and down method (OECD guideline no. 423) and fixed dose method (OECD guideline no. 420). Based on this guideline a limit test was to categorize the toxicity class $\left(\mathrm{LD}_{50}\right)$ of the compound. The limit test was performed at $2000 \mathrm{mg} / \mathrm{kg}$, p.o. A dose range of $20 \mathrm{mg} / \mathrm{kg}$, $40 \mathrm{mg} / \mathrm{kg}$ was selected for the pharmacological activity. For all the studies overnight fasted animal of either sex were used.

\subsection{Experimental design}

On prove day (day 5), Randomized animals are divided into experimental groups randomly $(n=6) . \mathrm{AlCl}_{3}$, Rivastigmine and Sinapic acid suspensions were made freshly each day for administration. Rats were administered with $\mathrm{AlCl}_{3}(175 \mathrm{mg} /$ $\mathrm{kg}$ ) orally from day 6 (i.e., $24 \mathrm{~h}$ after the completion of retention trial on day 5) to 25 days. $\mathrm{AlCl}_{3}$ was dissolved in distilled water and administered orally at a dose of $0.5 \mathrm{~mL} / 100 \mathrm{~g}$ body weight Standard drug (Rivastigmine- $2.5 \mathrm{mg} / \mathrm{kg}$ ), was suspended in $1 \%$ aqueous solution of Tween 80 was given orally from day 26 to 36 day. Test drug Sinapic acid (20 and $40 \mathrm{mg} / \mathrm{kg}$ ), suspended in a $1 \%$ aqueous solution of Tween 80 was given orally from day 26 to 36 day. Control group receive normal saline by respective route. The estimations of various neuro chemicals were done by various methods available in literature. The TNF $\alpha$ levels were estimated by ELISA kit. The groups were as follows.

Group I control Group (Normal saline $(0.9 \% \mathrm{NaCl})-5 \mathrm{~mL} / \mathrm{kg}$, p.o., from 6th- 36th day). 
Group II Untreated $\mathrm{AlCl}_{3}$-affected rats.

Group III Rivastigmine-treated $\mathrm{AlCl}_{3}$ - affected rats.

Group IV Sinapic acid (20 mg/kg, p.o.)-treated $\mathrm{AlCl}_{3}$ - affected rats.

Group V Sinapic acid (40 mg/kg, p.o.)-treated $\mathrm{AlCl}_{3}$ - affected rats

The water maze consisted of a circular tank $(150 \mathrm{~cm}$ diameter and $40 \mathrm{~cm}$ height). Water pool was divided into four equally spaced quadrants (north-east, south-east, south-west and north-west (NW)) along the circumference of the pool. An escape platform $(10 \mathrm{~cm}$ diameter) submerged $2 \mathrm{~cm}$ below the water surface was placed in NW quadrant. Rats were trained to locate the hidden platform at a fixed location in NW quadrant. All rats were subjected to one session of four trials per day for four consecutive days (0-4th day). During each trial, the animal was placed in each quadrant to eliminate quadrant effects. All rats were left in the platform for $30 \mathrm{~s}$ and then removed and towel dried. Rats failing to find the platform within $60 \mathrm{~s}$ were guided to the platform. On day 5 (Probe day/ Zero day), $24 \mathrm{~h}$ after previous training, escape platform was removed and probe trial was conducted. The cut-off time for animal to swim was set to $60 \mathrm{~s}$ before the end of session. Similarly, the retention trials were conducted on day $5,16,26$ and day 36 on different groups to evaluate memory. Time elapsed in escaping to the NW quadrant, i.e. escape latency time (ELT) and total time (TT) time spent in NW quadrant, was measured during the retention trials[24].

Using a digital photoactometer, locomotor activity was assessed in animals. The ambulatory movements were recorded over a period of 10 minutes and expressed in terms of total photo beam counts for 10 minutes per animal. Locomotor activity (L.A.)was assessed on day 5, 16, 26 and day 36 before probe trial in Morris's water maze[25].

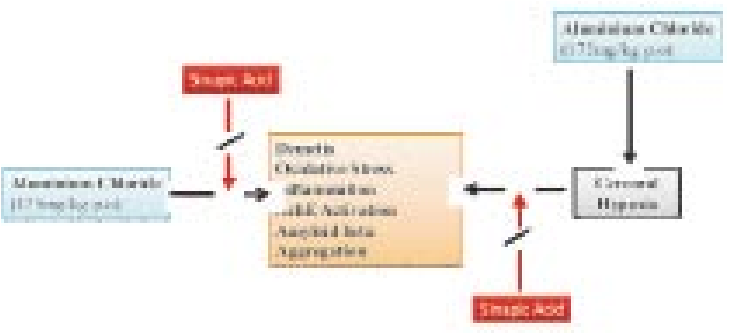

Figure 2. Proposed mechanism for therpeutic effect of Sinapic acid.

\subsection{Evaluation}

After $24 \mathrm{~h}$ of the experimental period (after 35 days), the animals were sacrificed and their brains were removed and weighed. The whole brain of each animal was dissected, thoroughly washed with ice-cold isotonic saline. A $10 \%$ issue homogenate was prepared in $0.1 \mathrm{M}$ phosphate buffer $\left(\mathrm{pH} 8\right.$, stored $2-8{ }^{\circ} \mathrm{C}$ ) for various neurochemical estimations and other anti oxidative parameters.

Acetyl choline esterase (AchE) activity: it was measured by Ellman method[26]. $0.4 \mathrm{~mL}$ supernatant of brain homogenate, $2.6 \mathrm{~mL}$ of 0.05 M phosphate buffer and $0.1 \mathrm{~mL}$ of $0.1 \mathrm{M}$ DTNB[5,5-dithiobis-(2- nitrobenzoic acid)] were processed and Measured the absorbance at $412 \mathrm{~nm}$ through U.V. spectrophotometry, until the reading was constant and then added $0.02 \mathrm{~mL}$ acetylthiocholine iodide (substrate). Immediately took absorbance at $412 \mathrm{~nm}$ for continue 7 minutes of the interval of one minute. The results were expressed as $\mathrm{nM} / \mathrm{L} / \mathrm{min} / \mathrm{gm}$ of tissue.

GSH was measured by the method described by Ellman[27-30]. Supernatant of brain homogenate, $10 \%$ TCA (1:1 ratio) were added and centrifuge at $1000 \mathrm{rpm}$ for 10 minutes. $0.05 \mathrm{~mL}$ supernatant, two $\mathrm{mL}$ of $0.3 \mathrm{M}$ dihyrogen phosphate, $0.25 \mathrm{~mL}$ freshly prepared DTNB were added and took absorbance at $412 \mathrm{~nm}$. The results were expressed as $\mathrm{nM} / \mathrm{mg}$ of protein.

Estimation of Catalase: Catalase activity was measured by Luck method[31], wherein the breakdown of $\mathrm{H}_{2} \mathrm{O}_{2}$ was measured. $0.05 \mathrm{~mL}$ supernatant of brain homogenate, three $\mathrm{mL} \mathrm{H}_{2} \mathrm{O}_{2}$ phosphate buffers were added and recorded change in absorbance for $2 \mathrm{~min}$. at the $30 \mathrm{~s}$ intervals at $240 \mathrm{~nm}$. The results were expressed as micromoles of $\mathrm{H}_{2} \mathrm{O}_{2}$ decomposed/min./mg/of protein.

Estimation of Superoxide dismutase (SOD): SOD activity was measured by Kono method[32]. The assay system consisted of EDTA $0.1 \mathrm{Mm}$, sodium carbonate $50 \mathrm{mM}$ and $96 \mathrm{mM}$ of nitro blue tetrazolium (NBT). In the cuvette, $2 \mathrm{~mL}$ of the above mixture, 0.05 $\mathrm{mL}$ supernatant of brain homogenate and $0.05 \mathrm{~mL}$ of hydroxylamine were added, and the auto-oxidation of hydroxylamine was measured for $2 \mathrm{~min}$. at the 30s intervals by measuring the absorbance at 560 $\mathrm{nm}$. The results were expressed as Units/mg protein.

Estimation of Nitrite: it was measured by Najmun method[33]. 0.2 $\mathrm{mL}$ of the supernatant of brain homogenate was mixed with freshly prepared Griess reagent solution and immediately took absorbance at $546 \mathrm{~nm}$. The results were expressed as $\mathrm{nM} / \mathrm{mg}$ of protein.

Histopathological study: The second portion of each brain was fixed in formalin buffer (10\%) for $24 \mathrm{~h}$. The brains were washed in tap water and then dehydrated using serial dilutions of alcohol (methyl, ethyl and absolute ethyl). Specimens were cleared in xylene and embedded in paraffin in a hot air oven at $56{ }^{\circ} \mathrm{C}$ for 24 h. Paraffin beeswax blocks were prepared for sectioning at $4 \mu \mathrm{m}$ using a microtome. The obtained tissue sections were collected on glass slides, deparaffinized and stained with hematoxylin and eosin stains[34] for histopathological examination using a light microscope.

\subsection{Statistical analysis}

The data was expressed as Mean \pm SEM. In all the tests, the criterion for the statistical significance was set at $P<0.05$. The data for all studies was analyzed using one-way ANOVA followed by Tukey-Kramer Multiple Comparisons test.

\section{Results}

\subsection{Acute toxicity study}

Sinapic acid did not show any sign and symptom of toxicity and mortality up to $2000 \mathrm{mg} / \mathrm{kg}$, p.o. 


\subsection{Effect of Sinapic acid on Aluminium chloride induced behavioural parameters}

\subsubsection{Effect of Sinapic acid on Aluminium chloride induced dementia of Alzheimer's type in rat using the Morris Water Maze}

The rat spends significantly more time in the target quadrant (NW) in search of the missing platform as compared to the time spent in other quadrants (SE, SW and NE) during the retention trial conducted on the 5th day (probe day). Control group showed the normal retrieval of memory on 36 th day[ELT $(5.15 \pm 0.08$ $P<0.001)$ and TT $(3.42 \pm 0.18 P<0.001)] . \mathrm{AlCl}_{3}$ treated rats (Group II) significantly raised ELT and reduced the time spent in the target quadrant $(\mathrm{NW})$ i.e. TT markedly in search of the missing platform during the retention trial on 16th, 26th and 36th day[ELT $(P<0.001)$ and TT $(P<0.001)]$ as compared to control group rats (Group, I). Untreated $\mathrm{AlCl}_{3}$-affected rats (Group III) significantly raised the ELT and reduced the TT during the retention trial on 16th and 26th day, but the rivistigmine-treated $\mathrm{AlCl}_{3}$ - affectedresulted in decreased in ELT and increased in TT during retention trial on 36th day, when compared to $\mathrm{AlCl}_{3}$ treated animals (Group II). Untreated $\mathrm{AlCl}_{3}-$ affected rats(Group IV and V) significantly raised the ELT and reduced in TT during the retention trial 16th and 26th day but the sinapic acid-treated $\mathrm{AlCl}_{3}$-affected ( 20 and $40 \mathrm{mg} / \mathrm{kg}$ ) rats resulted in decreased in ELT and increased in TT during retention trial on 36th day, ELT and TT when compared to $\mathrm{AlCl}_{3}$ treated animals (Group II) (Table 1 and Table 2).

\subsubsection{Effect of Sinapic acid on Aluminium chloride induced dementia of Alzheimer's type in rat using Photoactometer}

Locomotor activities (ambulatory movements) of rats were recorded for a period of $10 \mathrm{~min}$. and expressed in terms of total photo beam counts for $10 \mathrm{~min}$./animal. Control group rats (Group I) showed the normal locomotor activity on 36th day (149.2 \pm 1.63 counts/10 min). Aluminium chloride treated rats (Group II) resulted in a significant decreased in locomotor activity on 16th, 26th and 36th day $(P<0.001)$ as compared to control group rats (Group, I). $\mathrm{AlCl}_{3}$ pre-treated rats (Group III) resulted in a significant decreased in locomotor activity on 16th and 26th day, but the rivistigminetreated $\mathrm{AlCl}_{3}$-affectedresulted in a significant increased in locomotor activity on 36th day $(P<0.001)$ when compared to $\mathrm{AlCl}_{3}$ treated rats (Group II). $\mathrm{AlCl}_{3}$ pre-treated rats (Group IV and V) resulted in a significant decreased in locomotor activity on 16th and 26th day but sinapic acid-treated $\mathrm{AlCl}_{3}$-affected $(20 / 40 \mathrm{mg} / \mathrm{kg})$ resulted in a significant increased in locomotor activity $130.13 \pm 1.65$ and 138.2 $\pm 5.58(P<0.001)$ when compared to $\mathrm{AlCl}_{3}$ treated rats (Group II) ) (Table 3 ).

\subsubsection{Effect of Sinapic acid on biochemical Parameters}

The figures explicate the levels of AchE (Figure 3A), TBARS

Table 1

Effect of Sinapic acid on Aluminium chloride induced dementia of Alzheimer's type in rat using Morris Water Maze (Escape latency Time).

\begin{tabular}{lccc}
\hline \multirow{2}{*}{ Groups/ Treatment } & \multicolumn{2}{c}{ ELT (sec) } \\
\cline { 2 - 4 } & 5th day & 16th day & 26th day \\
\hline I (Control Group) & $4.98 \pm 0.1$ & $5.04 \pm 0.1$ & $5.03 \pm 0.1$ \\
II (Untreated AlCl3-affected rats) & $4.879 \pm 0.1$ & $14.0 \pm 0.05$ & $26.28 \pm 0.27$ \\
III(Rivastigmine-treated AlCl3- affected rats) & $4.98 \pm 0.13$ & $11.1 \pm 0.08$ & $19.32 \pm 0.28$ \\
IV (Sinapic acid (20mg/kg, p.o.)-treated AlCl3- affected rats) & $4.87 \pm 0.07$ & $11.0 \pm 0.12$ & $18.83 \pm 0.22$ \\
V (Sinapic acid (40mg/kg, p.o.)-treated AlCl3- affected rats) & $4.97 \pm 0.04$ & $12.94 \pm 0.04$ & $21.87 \pm 0.07$ \\
\hline
\end{tabular}

Data are mean \pm SEM values, $n=6$. Data were analyzed by One way ANOVA followed by Tukey-Kramer Multiple Comparisons test. $* P<0.05$, $* * P<0.01$, *** $P<0.001$ and nsp $>0.05$. a- compared with control, b-compared with inducer, NS Not significant, ELT- Escape latency Time.

Table 2

Effect of Sinapic acid on Aluminium chloride induced dementia of Alzheimer's type in rat using Morris Water Maze.

\begin{tabular}{lccc}
\hline Groups/ Treatment & & \multicolumn{2}{c}{ T.T (sec) } \\
\cline { 2 - 5 } & 5th day & 16th day & 26th day \\
\hline I (Control Group) & $3.53 \pm 1.01$ & $3.98 \pm 0.04$ & $3.55 \pm 0.05$ \\
II (Untreated AlCl3-affected rats) & $3.65 \pm 0.10$ & $3.35 \pm 0.13$ & $1.99 \pm 0.04$ \\
III(Rivastigmine-treated AlCl3- affected rats) & $3.62 \pm 0.09$ & $2.98 \pm 0.04$ & $1.20 \pm 0.06^{\mathrm{a}^{* * *}}$ \\
IV (Sinapic acid (20mg/kg, p.o.)-treated AlCl3- affected rats) & $3.57 \pm 0.12$ & $2.90 \pm 0.05$ & $1.78 \pm 0.02$ \\
V (Sinapic acid (40mg/kg, p.o.)-treated AlCl3- affected rats) & $3.64 \pm 0.11$ & $3.12 \pm 0.05$ & $2.8 \pm 0.15^{\mathrm{b}^{* * *}}$ \\
\hline
\end{tabular}

Data are mean \pm SEM values, $n=6$. Data were analyzed by One way ANOVA followed by Tukey-Kramer Multiple Comparisons test. $* P<0.05, * * P<0.01$, $* * * P<0.001$ and nsp $>0.05$. a- compared with control, b-compared with inducer, NS Not significant, T.T- Total Time.

Table 3

Effect of Sinapic acid on Aluminium chloride induced dementia of Alzheimer's type in rat using Photoactometer.

\begin{tabular}{|c|c|c|c|c|}
\hline \multirow{2}{*}{ Groups/ Treatment } & \multicolumn{4}{|c|}{ L.A (count/10min) } \\
\hline & 5th day & 16th day & 26th day & 36th day \\
\hline I (Control Group) & $150.27 \pm 1.71$ & $155.01 \pm 0.09$ & $151.99 \pm 0.64$ & $149.2 \pm 1.63^{\mathrm{b}^{* * * *}}$ \\
\hline II (Untreated $\mathrm{AlCl} 3$-affected rats) & $146.11 \pm 2.3$ & $83.13 \pm 0.116$ & $83.08 \pm 1.29$ & $95.2 \pm 1.02^{\mathrm{a}^{* * *}}$ \\
\hline III(Rivastigmine-treated $\mathrm{AlCl} 3$ - affected rats) & $149.95 \pm 2.71$ & $81.95 \pm 0.07$ & $79.13 \pm 2.07$ & $144.4 \pm 2.53^{\mathrm{b} * * *}$ \\
\hline IV (Sinapic acid (20 mg/kg, p.o.)-treated $\mathrm{AlCl} 3$ - affected rats) & $151.76 \pm 1.20$ & $86.07 \pm 0.09$ & $84.941 \pm 0.09$ & $130.122 \pm 1.65^{\mathrm{a}^{* *} \mathrm{~b}^{* * * *}}$ \\
\hline V (Sinapic acid (40 mg/kg, p.o.)-treated $\mathrm{AlCl} 3$ - affected rats) & $148.85 \pm 3.023$ & $89.20 \pm 0.18$ & $85.23 \pm 2.50$ & $138.2 \pm 5.58^{\mathrm{b}^{* * * *}}$ \\
\hline
\end{tabular}

Data are mean \pm SEM values, $n=6$. Data were analyzed by One way ANOVA followed by Tukey- Kramer Multiple Comparisons test. $* P<0.05$, $* * P<0.01$,

$* * * P<0.001$ and $\mathrm{nsp}>0.05$.a-compared with control, b-compared with inducer, NS Not significant, LA.-loco motor activity. 
(Figure 3B), Nitrite (Figure 3C), GSH (Figure 4D), Catalase (Figure $4 \mathrm{E}$ ), and SOD (Figure 4F) level in brain homogenate of control and experimental groups of rats. The levels of AchE, TBARS, and Nitrite were significantly elevated in Untreated $\mathrm{AlCl}_{3}$-affected rats as compared to a control group. The animals treated with revastigmine showed a significant reduction in the levels of AchE, TBARS, and Nitrite on 36th day of trial as compared with Untreated $\mathrm{AlCl}_{3}$ affected group. The elevated levels of AchE, TBARS, and Nitrite were declined up on treatment with sinapic acid in a dose dependent manner during the experimental trial as compared with Untreated $\mathrm{AlCl}_{3}$-affected group.

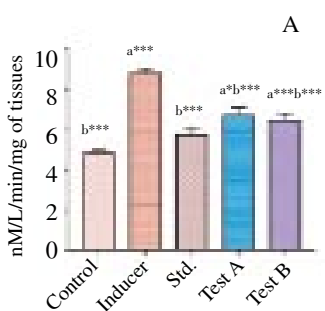

Acetyl Cholinesterase

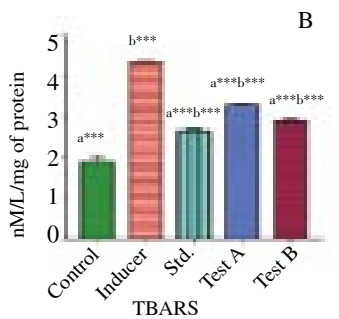

C

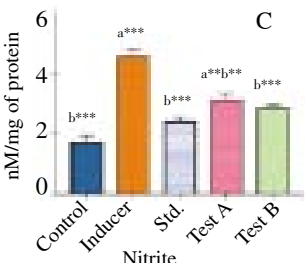

Figure 3. (A)Effect of Sinapic acid on Acetyl Cholinesterase level in brain. (B) Effect of Sinapic acid on TBARS level in brain (C) Effect of Sinapic acid on Nitrite level in brain. All values were represented as mean \pm SEM. Data are mean \pm SEM values, $n=6$. Data were analyzed by One way ANOVA followed by Tukey- Kramer Multiple Comparisons test. *p<0.05, **p<0.01, $* * * \mathrm{p}<0.001$ and $\mathrm{ns} \mathrm{p}>0.05$.a-compared with control, b-compared with inducer, NS Not significant. (where Inducer- Untreated $\mathrm{AlCl}_{3}$-affected rats, Std.- Rivastigmine-treated $\mathrm{AlCl}_{3}$ - affected rats, Test A- Sinapic acid (20mg/ $\mathrm{kg}$, p.o.)-treated $\mathrm{AlCl}_{3}$ - affected rats, and Test B- Sinapic acid (40mg/kg, p.o.)-treated $\mathrm{AlCl}_{3}$ - affected rats).
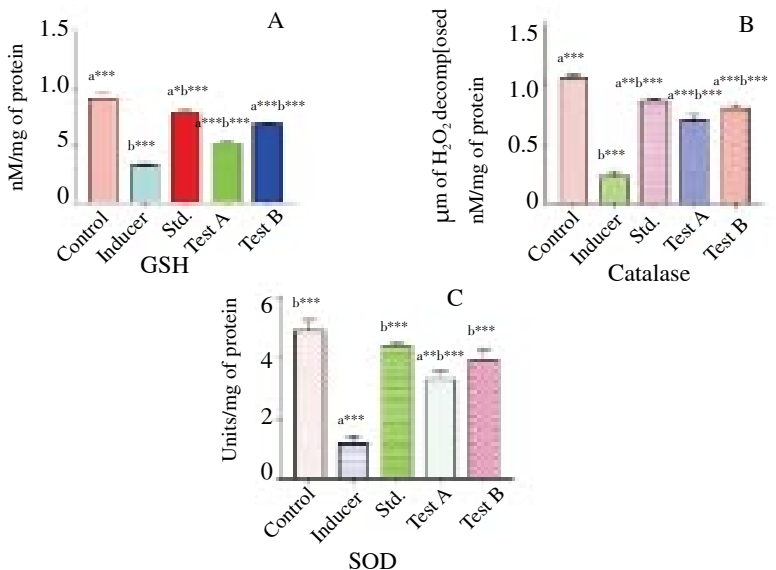

Figure 4. (D)Effect of Sinapic acid on GSH level in brain. (E) Effect of Sinapic acid on Catalase level in brain. (F) Effect of sinapic acid on SOD level in brain. All values were represented as mean \pm SEM. Data are mean \pm SEM values, $n=6$. Data were analyzed by One way ANOVA followed by Tukey- Kramer Multiple Comparisons test. ${ }^{*} \mathrm{p}<0.05$, $* * \mathrm{p}<0.01$, $* * * \mathrm{p}<0.001$ and $\mathrm{nsp}>0.05$.a-compared with control, b-compared with inducer, NS Not significant. (where Inducer- Untreated $\mathrm{AlCl}_{3}$-affected rats, Std.- Rivastigmine-treated $\mathrm{AlCl}_{3}$ - affected rats, Test A- Sinapic acid (20mg/ kg, p.o.)-treated $\mathrm{AlCl}_{3}$ - affected rats, and Test B- Sinapic acid (40mg/kg, p.o.)-treated $\mathrm{AlCl}_{3}$ - affected rats).

The levels GSH, Catalase and SOD were significantly decreased in Untreated $\mathrm{AlCl}_{3}$-affected rats as compared to a control group. The animals treated with revastigmine showed a significant increase in the levels of GSH, Catalase and SOD on 36th day of trial as

Table 4

Effect of sinapic acid on MAO level in Brain tissues.

\begin{tabular}{lccc}
\hline Groups/ Treatment & $\begin{array}{c}\text { MAO-A } \\
\text { (nmol/mg protein॰h) }\end{array}$ & $\begin{array}{c}\text { MAO- A } \\
\text { Inhibition (\%) }\end{array}$ & $\begin{array}{c}\text { MAO-B B } \\
(\mathrm{nmol} / \mathrm{mg} \text { protein॰h) }\end{array}$ \\
\hline Inhibition (\%)
\end{tabular}

Data are mean \pm SEM values, $n=6$.

Table 5

Effect of sinapic acid on $\mathrm{AlCl} 3$ induced toxicity with reference to change in Body and Brain weight.

\begin{tabular}{|c|c|c|c|c|c|c|}
\hline \multirow[t]{2}{*}{ Groups/ Treatment } & \multicolumn{2}{|c|}{ Change in Body Weight (gm) } & \multicolumn{2}{|c|}{ Brain weight (gm) } & \multicolumn{2}{|c|}{$\begin{array}{l}\text { Brain/Body weight } \\
\text { Ratio/100 gm of Rat }\end{array}$} \\
\hline & Male & Female & Male & Female & Male & Female \\
\hline I (Control Group) & $+2.54 \pm 0.21$ & $3.54 \pm 0.34$ & $1.24 \pm 0.4$ & $1.32 \pm 0.76$ & 1.12 & 1.09 \\
\hline II (Untreated AlCl3-affected rats) & $-1.24 \pm 0.25$ & $0.29 \pm 0.1$ & $0.89 \pm 0.25$ & $0.78 \pm 0.23$ & 0.74 & 0.51 \\
\hline III(Rivastigmine-treated AlCl3- affected rats) & $-2.89 \pm 0.56$ & $-2.58 \pm 0.78$ & $0.98 \pm 0.32$ & $1.05 \pm 0.56$ & 0.94 & 0.98 \\
\hline IV (Sinapic acid (20mg/kg, p.o.)-treated $\mathrm{AlCl} 3-$ affected rats) & $-3.54 \pm 0.56$ & $-2.89 \pm 0.87$ & $1.08 \pm 0.54$ & $1.2 \pm 0.21$ & 0.89 & 0.85 \\
\hline $\mathrm{V}$ (Sinapic acid (40mg/kg, p.o.)-treated $\mathrm{AlCl} 3$ - affected rats) & $-3.02 \pm 1.03$ & $-2.54 \pm 0.89$ & $1.3 \pm 0.52$ & $1.05 \pm 0.35$ & 0.79 & 0.98 \\
\hline
\end{tabular}

Data are mean \pm SEM values, $n=6$. (male-2, Female-4). 
compared with Untreated $\mathrm{AlCl}_{3}$-affected group. The reduced levels of GSH, Catalase and SOD were increased significantly with a dose of $40 \mathrm{mg} / \mathrm{kg}$ of sinapic acid as compared with Untreated $\mathrm{AlCl}_{3}$ affected group.

\subsubsection{Effect of sinapic acid on brain TNF- Level in $\mathrm{AlCl}_{3}$ induced dementia}

All the treated animals showed an increase in brain TNF- $\alpha$ level (Fig 5). Sinapic acid treatment produced a significant and dose dependent reduction in TNF- $\alpha$ levels as compared to control.

Untreated $\mathrm{AlCl}_{3}$-affected rats showed decrease in body weight and brain weight while other groups did not show any marked deference in body and brain weight of rats.

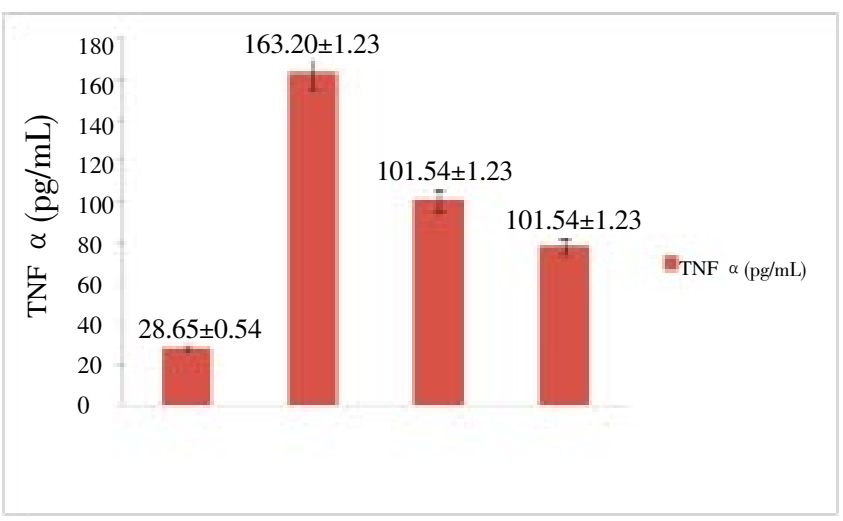

Figure 5. Effect of Sinapic acid on TNF level in brain cortex. All values were represented as mean \pm SEM. Data are mean \pm SEM values, $n=6$. Data were analyzed by One way ANOVA followed by Tukey- Kramer Multiple Comparisons test. ${ }^{*} \mathrm{p}<0.05$, $* * \mathrm{p}<0.01$, $* * * \mathrm{p}<0.001$ and $\mathrm{nsp}>0.05$.a-compared with control, b-compared with inducer, NS Not significant. (where I- control, II-Untreated $\mathrm{AlCl}_{3}$-affected rats, IV- Test A- Sinapic acid $(20 \mathrm{mg} / \mathrm{kg}$, p.o. $)$ treated $\mathrm{AlCl}_{3}$ - affected rats, and V-Test B- Sinapic acid (40mg/kg, p.o.)treated $\mathrm{AlCl} 3$ - affected rats).

\subsection{Histopathological study of the rat brain in Aluminium chloride-induced dementia of Alzheimer's type}

In normal control animals (A), neuronal cells were active and relatively packed with prominent nuclei.

In aluminium chloride treated group (B), spongy cell, neuronal necrosis. Cells degenerated with small nuclei leading to eosinophilic deposition.

In standard drug treated group (rivastigmine $2.5 \mathrm{mg} / \mathrm{kg}$ ) (C) treated group, the cells undergone slight neuronal necrosis and packed nuclei.

In Test A (sinapic acid $20 \mathrm{mg} / \mathrm{kg}$ ) (D) few cells undergo neuronal decongestion whereas Test B (sinapic acid $40 \mathrm{mg} / \mathrm{kg}$ ) (E), showed significant improvement in the group there is no cell degeneration with prominent nuclei (Figure 6).

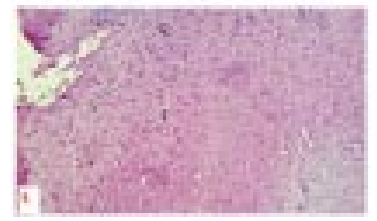

A Control (Group I)

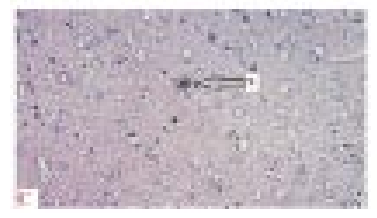

C

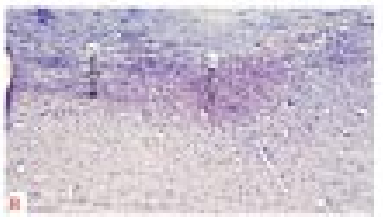

B Inducer (Group II)

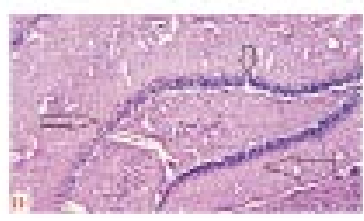

D Test A (Group IV)

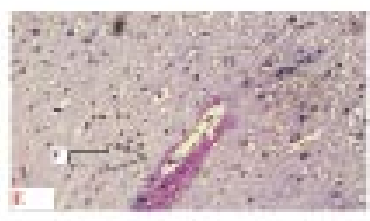

E Test A (Group V)

Figure 6. Histopathology of brain (cerebral cortex) showing Neuronal degeneration and inflammation. (D: Cellular degeneration, $\mathrm{V}$ : Neuronal vacuolation, $\mathrm{N}$ : Necrosis). (where Inducer- Untreated $\mathrm{AlCl}_{3}$-affected rats, Std.- Rivastigmine-treated $\mathrm{AlCl}_{3}$ - affected rats, Test A-Sinapic acid (20mg/kg, p.o.)-treated $\mathrm{AlCl}_{3}$ - affected rats, and Test B- Sinapic acid (40mg/kg, p.o.)-treated $\mathrm{AlCl}_{3}$ - affected rats).

\section{Dicussion}

$\mathrm{AD}$ is now the most common cause of dementia[35]. The incidence of AD increases with age[36]. Impairment of short-term memory usually is the first clinical feature. When the disease progresses, additional cognitive abilities are impaired, as the ability to calculate, and use common objects and tools[7].

Aluminium found in our daily life as in drinking water, soil and tooth paste, moreover, it is used to manufacture cooking utensils. Aluminium is a non-redox active metal which is capable of increasing the cellular oxidative milieu by potentiation of pro-oxidant properties of transition metals such as iron and copper[37]. It leads to oxidative deterioration of cellular lipids, proteins and DNA[38]. Lipid peroxidation can cause tissue damage under chronic condition[39,40] therefore, Aluminium can be considered as a contributing factor in AD. After chronic exposure, aluminium accumulates in all brain regions with greater accumulation in cortex and hippocampus[41-43]. Hippocampus and frontal cortex play an important role in learning and memory[44], which is severely affected in neurodegenerative disorders such as AD and Parkinson disease (PD).

It is a potent cholinotoxin and causes apoptotic neuronal loss which is a characteristic symptom of neurodegeneration associated with $\mathrm{AD}[49]$.

Chronic administration of aluminium chloride results in progressive deterioration of spatial memory in Morris water maze task 
paradigms. It leads to impairment of glutamate-NO-cGMP pathway to the cerebellum of rats[50]. In our study, chronic administration of aluminium chloride resulted in marked oxidative stress as indicated by an increase in lipid peroxidation, nitrite levels, decrease in reduced glutathione levels, Catalase and superoxide dismutase activity. This could be due to the reduced axonal mitochondria turnover, disruption of Golgi and reduction of synaptic vesicles induced by aluminium treatment, which results in release of oxidative products like malondialdehyde[TBARS], carbonyls, peroxynitrites and enzymes like superoxide dismutase within the neurons[51].

Acetyl cholinesterase inhibitors are the only agents approved by the Food and Drug Administration (FDA) for the treatment of AD. Rivastigmine was used as standardized drug as it is the only proven pharmacological therapy for the symptomatic treatment of AD[52]. Impaired cholinergic transmission is one of the complications seen in the etiopathogenesis of memory deficit in AD. The neurodegeneration in frontal cortex and hippocampus areas within the brain[53] resulting in impaired cholinergic transmission by two ways. Firstly, in AD patients, it occurs either due to (I) decline in Ach release (ii) decreased choline acetyltransferase activity (ChAT), which results in the scarcity of Acetylcholine[54,55]. Secondly, elevated acetyl cholinesterase (AchE) enzyme further adds to scarcity of Ach at the synapse by degrading the available Ach. This degradation of Ach is abolished by rivastigmine (AchE inhibitor) so it's effective in AD through improvement in cholinergic transmission.

Sinapic acid (Hydroxycinnamic acid) belongs to the class of phenolic acids with bioactive carboxylic acids; the class mainly includes caffeic acid, ferulic acid, and sinapic acid[56,57]. It is a frequent phytochemical in the human diet. It's a potent inhibitor of an enzyme AchE[58,59]. The possible mechanism by it inhibits cerebral hypoxia[60] and improved memory disturbance by activating cholinergic function[Acetylcholine (Ach) and choline acetyltransferase (ChAT)].

Chronic aluminium exposures have been reported to result in cognitive[58] and locomotor impairment[59]. The cognitive deficit is evident to declined performance in Morris water maze test[60] and radial arm maze test[61]. In our study, aluminium treatment resulted in behavioral changes such as a spatial memory deficit, indicated by increased escape latency and decreased in time spent in target quadrant[NW]. Rivastigmine and sinapic acid antagonized the spatial memory deficit caused by aluminium. This suggests the neuro protective role of sinapic acid in correcting cognitive dysfunction associated with aluminium exposure.

Assessment of locomotor activity is a requirement for evaluating any possible CNS depressant/stimulant effect of interventions on animals. Similar to previous reports[60], a decline in locomotor activity in aluminium treated rats was observed, indicating the CNS depressant effect of chronic aluminium exposure. Treatment with rivastigmine and sinapic acid corrected the locomotor incoordination caused by aluminium chloride.

Histopathological examination of Aluminium chloride induced AD brain showed spongy cell, neuronal necrosis. Cells degenerated with small nuclei leading to eosinophilic deposition. However, besides these pathological hallmarks, AD brain exhibited a clear evidence of chronic inflammation and oxidative damage[60,61]. These are also thought to play a significant role at the onset and progression of AD. Present study also supports an evidence of inflammation with high concentration of TNF $\alpha$ in brain tissues as compared with control rats. Administration of rivastigmine and sinapic acid in $\mathrm{AD}$ rats improved the pathogenesis of $\mathrm{AD}$ as demonstrated by an improvement in the behavioral (levels of activity and motor coordination), Inflammatory (TNF- $\alpha$ ) and biochemical parameters in the brains, which was further confirmed by an improvement in brain tissue characteristics on histopathological analysis.

It is well established that aluminium is a neurotoxic agent that induces the production of free radicals and various inflammatory cascade in the brain[62,63]. Accumulation of free radicals may cause degenerative events of aging such as $\mathrm{AD}$ and because sinapic acid showed its potential against this neurotoxic agent so it should be used in dementia or $\mathrm{AD}$

From the above pharmacological, biochemical and histopathological studies, it has been concluded that at the doses of $40 \mathrm{mg} / \mathrm{kg}$, p.o. of sinapic acid possesses the potentially protective effect agains aluminium chloride induced dementia of Alzheimer's type in rats.

Sinapic acid provides a significant effect against neuroinflammatory disorders because of its TNF- $\alpha$ modulatory activity.

Sinapic acid could be used as choline esterase inhibitors with an adjuant therapy in AD disease.

The compound is also proved to be as MAO modulator so it may be beneficial against other neurodegenerative disease.

\section{Conflict of intrest statement}

The authors declare that there is no conflict of interests regarding the publication of this paper

\section{Funding}

Instituional funding has been provided to carry out the research.

\section{Authors contribution}

Souravh Bais -ES-supervision of Practical works and participated in the design to the study and performed the statistical analysis. Yash Prashar- FG-conceived of the study, and participated in its design and coordination and helped to draft the manuscript. Renu 
Kumari- conceived of the study, and participated in its design and coordination and helped to draft the manuscript.

\section{References}

[1] World Health Organization (1992) International classification of diseases 10th revision. Geneva. WHO.

[2] Ferri CP, Prince M, Bravne C. Alzheimer's disease International. Global prevalence of dementia: A Delhi consensus study. Lancet 2005; 366 2112-2117.

[3] Thomas H, Rai G. The aetiology and pathology of dementia. Hospit Pharm 2001; 8: 33-40.

[4] Larson EB, Kukull WA, Katzman RL. Cognitive impairment: Dementia and Alzheimer's disease. Anпи Rev Public Health 1992; 13: 431-449.

[5] Birks J. Cholinesterase inhibitors for Alzheimer's disease. The Cochrane database of systematic reviews $1 ; 2006$.

[6] Cumings JL. Alzheimer's disease. N Engl J Med 2004; 351: 56-67.

[7] Kimura R, Ohno M. Impairments in remote memory stabilization precede hippocampal synaptic and cognitive failures in 5XFAD Alzheimer mouse model. Neurobiol Dis 2009; 33: 229-235.

[8] Terry AV Jr, Buccafuso JJ. The cholinergic hypothesis of age and Alzheimer's disease-related cognitive deficits: Recent challenges and their implications for novel drug development. J Pharmacol Exp Ther 2003; 306: $821-827$.

[9] Lon AD, Elena KF, Brian RO. Cholinesterase inhibitors improve visual attention in drivers with Alzheimer's disease. Alzheimer and Dementia 2008; 4: 498

[10]Liu Y, Fiskuma G, Schubert D. Generation of reactive oxygen species by the mitochondrial electron transport chain. J Neurochem 2002; 80: 780787.

[11]Sherer TB, Richardson JR, Testa CM, Seo BB, Panov AV, Yagi T, et al. Mechanism of toxicity of pesticides acting at complex 1: relevance to environmental etiologies of Parkinson's disease. J Neurochem 2007; 100(6): 1503-1504.

[12]Natella F, Nardini M, Di Felice M. Benzoic and cinnamic acid derivatives as antioxidants: structure activity relation. J Agric Food Chem 1999; 47 1453-1459.

[13]Kikuzaki H, Hisamoto M, Hirose K. Antioxidant properties of ferulic acid and its related compounds. J Agric Food Chem 2002; 50: 2161$2168 .=$

[14]Silambarasan T, Manivannan J, Priya MK, Suganya N, Chatterjee S, Raja B. Sinapic acid protects heart against ischemia/reperfusion injury and H9c2 cardiomyoblast cells against oxidative stress. Biochem Biophys Res Cn 2014; 456(4): 853-859.

[15]Kyung-Jin Yun, Duck-Jae Koh, Shi-Hye Kim. Anti-inflammatory effects of sinapic acid through the suppression of inducible nitric oxide synthase, cyclooxygase-2, and proinflammatory cytokines expressions via nuclear factor-kappa B inactivation. J Agric Food Chem 2008; 56(21): 1026510272.
[16]Yoon BH, Jung JW, Lee JJ. Anxiolytic-like effects of sinapic acid in mice. Life Sci 2007; 81(3): 234-240

[17]Chandrasekaran B, Jayachandran M, Rajamanickam V. Anticancer Effects of Sinapic Acid on Human Colon Cancer Cell Lines HT-29 and SW480 Department of Biochemistry and Biotechnology. Available from:www.ijpba.info/ijpba/index.php/ijpba/article/download/1342/957.

[18]Lee HE, Kim DH, Park SJ. () Neuroprotective effect of sinapic acid in a mouse model of amyloidal $\beta$ (1-42) protein-induced Alzheimer's disease. Pharmacol Biochem Behav 2012: 3(2): 260-266.

[19]Shin DS, Kim KW, Chung HY, Yoon S, Moon JO. Effect of sinapic acid against dimethylnitrosamine-induced hepatic fibrosis in rats. Arch Farm Res 2013; 36(5): 608-618.

[20]Kelly C, Jones O, Barnhart C, Lajoie C. Effect of furfural, vanillin and syringaldehyde on Candida guilliermondii growth and xylitol biosynthesis. In, Biotechnology for Fuels and Chemicals. Adney WS, McMillan JD, Mielenz J, Klasson KT editors. Humana Press, New York, NY, USA; 2008. p. 615-626.

[21]Roy SJ, Prince PSM () Protective effects of sinapic acid on cardiac hypertrophy, dyslipidaemia and altered electrocardiogram in isoproterenol-induced myocardial infarcted rats. Europ J Pharmacol 2013; 699(1-3), 213-218.

[22]Prince PSM. A biochemical, electrocardiographic, electrophoretic, histopathological and in vitro study on the protective effects of epicatechin in isoproterenol-induced myocardial infarcted rats. Europ $J$ Pharmacol 2011; 671(1-3): 95-101.

[23]Ader P, Greacher B, Langguth P, Scharrer E, Wolffram S. Cinnamate uptake by rat small intestine: transport kinetics and transepithelial transfer. Experimental Physiology 1996; 81(6): 943-955.

[24]Cavin JF, Barthelmebs L, Guzzo J. Purification and chractersterization of an inducile p-coumaric acid decarboxylase from Lactobacillus plantarum. FEMS Microbiol Lett 1997; 147(2): 291-295.

[25]Griffiths LA. Metabolism of sinapic acid and related compounds in the rat. Biochem J 1969; 113: 603-609.

[26]Morris R. Developments of a water maze procedure for studying spatial learning in the rat. J Neurosci Methods 1984; 1: 47-60.

[27]Ellman GL, Courtney V, Andres Jr, Featherstone RM () A new and rapid colorimetric determination of Acetylcholinesterase activity. Biochem Pharmacol 1961; 7(2): 88-95.

[28]Beutler E, Duron O, Kelley BM. Improved methods for determination of blood glutathione. J Lab Clin Med 1963; 61: 882-888.

[29]Jollow DJ, Mitchell JR, Zamoaglione N, Gillette JR () Bromobenzene induced livernecrosis: protective role of glutathione and evidence for 3,4-bromobenzenoxides as the hepatotoxic intermediate. Pharmacology 1974; 11: 151-169.

[30]Luck H. Catalase. Methods of enzymatic analysis Bergmeyer HU (EDs). Academic Press, New York; 1971. p. 885-893.

[31]Armstrong DM, Ikonomovic MD, Sheffield R, Wenthold RJ () AMPA selective glutamate receptors subtype immunoreactivity in the entorhinal cortex of non-demented elderly patients with Alzheimer's disease. Brain 
Res 1994; 639: 207-216.

[32]Ohkawa H, Ohishi N, Yagi K. Assay for lipid peroxides in animal tissues by thiobarbituric acid reaction. Anal Biochem 1979; 95: 351-358.

[33]Yagi K. Simple procedure for specific assay of lipid hydroperoxides in serum of plasma. Free radical and antioxidant protocols 1998; 108: 101106

[34]Nazmun Lyle, Dipankar B, Tapas KS, Santanu M, Suhrita P, Suparna

C, Antony G. Stress modulating antioxidant effect of Nardostachys jatamansi. Indian journal of Biochemistry and Biophysics 2009; 46: 9398.

[35]Banchroft JD, Steven A, Turner DR. Theory and practice of histological technique. New York: Churchill Livingstone; 1996.p. 4.

[36]Hansson O, Zetterberg H, Buchhave P, Londos E, Blennow K. Association between CSF biomarkers and incipient Alzheimer's disease in patients with mild cognitive impairment: a follow-up study. Lancet Neurol 2006; 5: 228-234.

[37]Maccioni RB, Muñoz JP, Barbeito L. The molecular bases of Alzheimer's disease and other neurodegenerative disorders. Arch Med Res 2001; 32 367-381.

[38]Bjertness E, Candy JM, Torvik A, Ince P, McArthur F, Taylor GA Content of brain aluminium is not elevated in Alzheimer's disease. Alzheimer Dis Assoc Disord 1996; 10(3): 171-174.

[39]Sargazi M, Shenkin A, Roberts NB () Aluminium-induced injury to kidney proximal tubular cells: Effects on markers of oxidative damage. $\mathbf{J}$ Trace Elem Med Biol 2006; 19: 267-273.

[40]Nourooz-Zadeh J, Rahimi A, Tajaddini-Sarmadi J, Tritschler H, Rosen P. Relationships between plasma measures of oxidative stress and metabolic control in NIDDM. Diabetologia 1997; 40: 647-653.

[41]Campbell A. The potential role of aluminium in Alzheimer's disease. Nephrol Dial Transplant 2002; 17(2): 17-20.

[42]Deloncle R, Guillard O. Mechanism of Alzheimer's disease: arguments for a neurotransmitter-aluminium complex implication. Neurochemical Research 1990; 15(12): 1239-1245.

[43]Julka D, Vasishta RK, Gill KD. Distribution of aluminum in different brain regions and body organs of rat. Biological Trace Element Research 1996; 52(2): 181-192.

[44]Kaur A, Gill KD. Possible peripheral markers for chronic aluminium toxicity in Wistar rats. Toxicol Ind Health 2006; 22(1): 39-46.

[45]Buckner RL, Kelley WM, Petersen SE. Frontal cortex contributes to human memory formation. Nature Neuroscience; 2(4): 311-314

[46]Gulya K, Rakonczay Z, Kasa P. Cholinotoxic effects of aluminium in rat brain. J Neurochem 1990; 54: 1020-1026.

[47]Canales JJ, Corbalàn R, Montoliu C, Llansola M, Monfort P, Erceg S. Aluminium impairs the glutamate-nitric oxide-cGMP pathway in cultured neurons and in rat brain in vivo: molecular mechanisms and implications for neuropathology. J Inorg Biochem 2001; 87: 63-69.

[48]Bharathi P, Shamasundar NM, Sathyanarayana Rao TS, Naidu MD,

Ravid R, Rao KSJ. A new insight on Al-maltolate-treated aged rabbits as Alzheimer's animal model. Brain Res Rev 2006; 52: 275-292.
[49]Mayeux R, Sano M. Treatment of Alzheimer's disease. N Engl J Med 1999; 341: 1670-1679.

[50]Francis PT, Sims NR, Procter AW, Bowen DM. Cortical pyramidal neurone loss may cause glutamatergic hypoactivity and cognitive impairment in Alzheimer's disease: investigative and therapeutic perspectives. J Neurochem 1993; 60: 1589-1604.

[51]Rodriguez-Puertas R, Pazos A, Zarranz JJ, Pascual J. Selective cortical decrease of high-affinity choline uptake carrier in Alzheimer's disease: an autoradiographic study using 3Hhemicholinium- 3. Journal of Neural Transmission 1994; 3: 161-169.

[52]Hammond P, Brimijoin S. Acetylcholinesterase in Huntington's and Alzheimer's diseases: simultaneous enzyme assay and immunoassay of multiple brain regions. Journal of Neurochemistry 1988; 50(4): 11111116.

[53]Fishman EB, Siek GC, MacCallum RD, Bird ED, Volicer L, Marquis JK. Distribution of the molecular forms of acetylcholinesterase in human brain: alterations in dementia of the Alzheimer type. Annals of Neurology 1986; 19(3): 246-252.

[54]Niciforovic N, Abramovic H. Sinapic acid and its derivatives: natural sources and bioactivity. Comprehensive Reviews in Food Science and Food Safety 2014; 13(1): 34-51.

[55]Bunzel M, Ralph J, Kim H. Sinapate dehydrodimers and sinapateferulate heterodimers in cereal dietary fibre. J Agric Food Chem 2003 ; 51: $1427-1434$.

[56]He L, Li HT, Guo SW, Liu LF, Qiu JB, Li F, Cai BC. Inhibitory effects of Sinapine on activity of Acetylcholinesterase in cerebral homogenate and blood serum of rats. Zhongguo Zhong Yao Za Zhi 2008; 33: 813-815.

[57]Ferreres F, Fernandes F, Sousa C, Valentao P, Pereira JA, Andrade PB. Metabolic and bioactivity insights into Brassica oleracea var. Acephala. $J$ Agric Food Chem 2009; 57: 8884-8892.

[58]Fumito K, Yukinobu I, Mitsuo T, Takuji Y, Yasushi I, Shuichi, T, Masaki A. Cerebral protective and cognition-improving effects of sinapic acid in rodents. Biol Pharm Bull 2007; 30(3): 514-519.

[59]Erazi H, Sansar W, Ahboucha S, Gamrani H. Aluminum affects glia system and behavior of rats. Comptes Rendus Biologies 2010; 333(1) 23-27.

[60]Khan KA, Kumar N, Nayak PG. Impact of caffeic acid on aluminium chloride-induced dementia in rats. J Pharm Pharmacol 2013; 65(12): $1745-1752$.

[61]Abdel-Aal RA, Assi AAA, Kostandy BB. Rivastigmine reverses aluminum-induced behavioral changes in rats. Europ J Pharmacol 2011; 659(2-3): 169-176.

[62]Pratico D, Trojanowski JQ. Inflammatory hypotheses novel mechanisms of Alzheimer's neurodegeneration and new therapeutic targets? Neurobiol Aging 2000; 21: 441-445.

[63]Pratico D, Delanty N. Oxidative injury in diseases of the central nervous system focus on Alzheimer's disease. Am J Med 2000; 109: 577-585. 